\title{
Álgebra para a formação do professor
}

Marcelo Bergamini Campos ${ }^{1}$

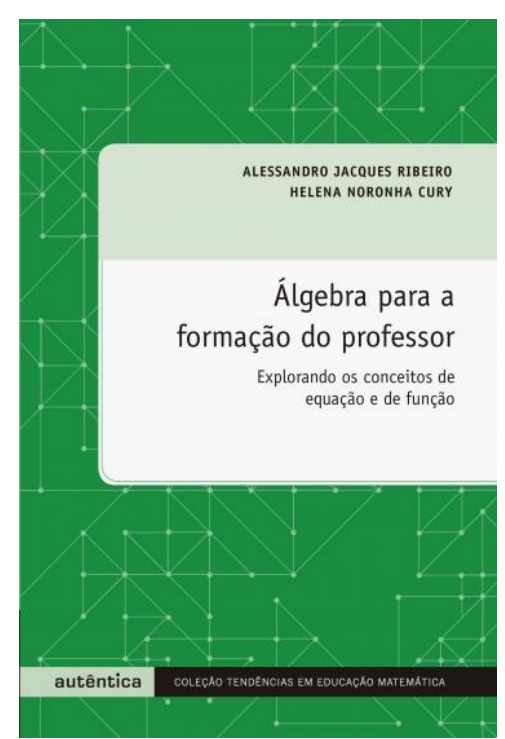

Ribeiro, Alessandro Jacques \& Cury, Helena Noronha. (2015). Álgebra para a formação do professor. Belo Horizonte: Autêntica. (Coleção Tendências em Educação Matemática).

\section{Resenha}

Os autores desta obra, Alessandro Jacques Ribeiro e Helena Noronha Cury, são renomados pesquisadores. Ele tem uma vasta produção sobre os processos de ensino e aprendizagem de Álgebra e ela, importantes estudos sobre a análise de erros. Em comum têm o interesse de investigar temas relacionados à formação de professores. Dessa forma, reúnem seus campos de pesquisas para apresentar um livro em que abordam os conceitos de equação e de função sobre a perspectiva da formação do professor de Matemática.

Ribeiro e Cury discutem a importância da Álgebra na Educação Básica e as dificuldades encontradas não somente pelos alunos, mas também pelos professores no

\footnotetext{
${ }^{1}$ Mestre em Educação Matemática pela Universidade Federal de Juiz de Fora (UFJF), Juiz de Fora/MG. Licenciado em Matemática pela Fundação Presidente Antônio Carlos, Barbacena/MG. Professor da Escola Municipal Sebastião Francisco do Vale, Barbacena/MG, Brasil. E-mail: marcelo.bergamini@hotmail.com
} 
http://periodicos.sbu.unicamp.br/ojs/index.php/zetetike

processo de ensino-aprendizagem desse tema. Com a intenção de desenvolver um estudo mais apurado sobre o assunto, selecionam dois tópicos: equações e funções. Ao longo da obra é possível perceber que eles defendem a necessidade de uma ruptura com a perspectiva adotada no ensino tradicional que privilegia a mecanização e a reprodução de técnicas e procedimentos.

No início do primeiro capítulo, intitulado "A Álgebra, seu ensino e sua aprendizagem", os autores defendem a proposta de abordagem da Álgebra, desde os anos iniciais do ensino, como fio condutor do currículo escolar.

Investigações sobre o tema são citadas, mostrando a existência de diversas concepções do que sejam Álgebra e pensamento algébrico. Eles buscam evidenciar que os reflexos dessas diferentes concepções podem ser percebidos nas atividades propostas nos livros didáticos ou nas orientações disponibilizadas em documentos oficiais.

Ao longo do capítulo apontam problemas e deficiências no ensino e aprendizagem de Álgebra, em que as equações e as funções são "frequentemente compreendidas como um 'amontoado' de símbolos, regras e procedimentos, muitas vezes desprovidos de significado" (Ribeiro \& Cury, 2015, p. 20). Essa é uma perspectiva que vem na contramão das orientações dos documentos oficiais e das pesquisas desenvolvidas em Educação Matemática as quais destacam a importância de estimular os estudantes a investigar padrões, buscar regularidades e desenvolver a capacidade de abstração e generalização.

Com relação à formação dos professores, pesquisas citadas no texto sinalizam que muitos docentes têm também uma concepção de equação ou função fortemente associada a aspectos procedimentais e à utilização de regras e técnicas.

A História da Matemática é o fio condutor do segundo capítulo, apresentado com o título "Epistemologia dos conceitos de equação e de função". Os autores fazem uma análise da "trajetória epistemológico-histórica dos conceitos de equação e função, identificando como diferentes povos, em diferentes épocas, concebiam tais conceitos" (Ribeiro \& Cury, 2015, p. 29).

Conforme foi sinalizado no primeiro capítulo, é possível identificar com mais clareza neste momento que a análise desses conceitos é desenvolvida a partir de quatro espaços geográficos e momentos históricos bem delimitados. Inicialmente os autores discutem as concepções dos povos babilônicos e egípcios no mundo antigo. Na sequência, a análise voltase para a civilização grega, principalmente no período helenístico, seguindo para as transformações observadas pelos povos hindus e árabes durante a Idade Média, finalizando com as concepções dos matemáticos europeus a partir do Renascimento. Os autores articulam, de forma consistente, essas quatro fases, pontuando semelhanças e diferenças, além de destacar as contribuições desses povos no desenvolvimento das concepções algébricas.

O terceiro capítulo é intitulado "Os documentos, os exames e as produções que abordam o ensino de equações e funções". A princípio, o foco é direcionado à apresentação e 
http://periodicos.sbu.unicamp.br/ojs/index.php/zetetike

à análise de investigações que abordam os diferentes tipos de conhecimentos necessários ao professor de Matemática e que não são adquiridos apenas na sua formação inicial.

$\mathrm{Na}$ sequência, os autores analisam documentos oficiais, pesquisas acadêmicas e também avaliações em larga escala que são vistos como fontes adicionais de conhecimentos para o professor. Eles desenvolvem uma análise das informações e das sugestões que podem ser obtidas nesses diferentes materiais no que diz respeito ao ensino de Álgebra. Exemplos de questões apresentadas em avaliações externas ou processos seletivos são analisados a partir das ideias de perfil conceitual de equação e de função, discutidos no primeiro capítulo.

Entendendo a necessidade de ampliar a visão do professor e também refletir sobre lacunas na sua formação, Ribeiro e Cury apontam no quarto capítulo, intitulado "Dificuldades encontradas na aprendizagem de equações e funções: alguns exemplos", a importância da análise dos erros apresentados pelos estudantes. Os autores defendem a ideia de que estes erros devem ser analisados pelo professor e também constituir objeto de discussão em cursos de formação.

Apoiados em uma série de investigações, abordam dificuldades encontradas por estudantes da Educação Básica e também de cursos de licenciatura na resolução de equações. Na sequência, exploram dificuldades na aprendizagem de funções. Dessa forma, ao longo do capítulo, o leitor encontra exemplos de soluções e resoluções incorretas apresentadas em diferentes segmentos de ensino. A análise dessas dificuldades é articulada aos diferentes tipos de conhecimentos do professor abordados anteriormente.

No quinto capitulo, "Atividades algébricas para o trabalho com equações e funções", há diversas sugestões de situações-problema que podem ser utilizadas em diferentes níveis de ensino.

Os problemas apresentados não são situações inéditas, desenvolvidas pelos autores, ao contrário, são adaptações ou reproduções de fontes diversas. No entanto, a leitura do capítulo pode trazer reflexões sobre o trabalho com a Álgebra em sala de aula ou na formação dos professores. De fato, não apenas por meio das atividades apresentadas, mas também das abordagens sugeridas, percebe-se a intenção de contribuir para que os alunos desenvolvam uma compreensão sobre os conceitos, em detrimento de uma simples memorização de regras. Os autores voltam a defender a importância de que os estudantes ampliem a capacidade de estabelecer generalizações, utilizar a linguagem algébrica ou encontrar padrões numéricos e geométricos. A possibilidade de estabelecer conexões do estudo da Álgebra com a Aritmética ou Geometria é colocada em evidência em diversos momentos.

A apresentação de cada atividade é seguida por comentários a partir dos quais o leitor pode perceber uma articulação com conceitos explorados nos capítulos anteriores. Ribeiro e Cury retomam a análise dos erros ou das dificuldades na resolução das atividades propostas, ratificando a perspectiva de que essas situações podem ser discutidas com os próprios alunos em sala de aula ou ainda em cursos de formação de professores, oportunizando a compreensão das dificuldades dos estudantes. 
http://periodicos.sbu.unicamp.br/ojs/index.php/zetetike

Nas considerações finais, os autores apontam para a existência de uma relação assíncrona. Por um lado, há um crescente número de investigações em Álgebra com foco no ensino dos conceitos de equações ou funções na Educação Básica. Por outro, não tem sido observado um impacto significativo dessas pesquisas na aprendizagem dos conceitos por parte dos alunos ou mesmo dos professores que atuam nesse segmento de ensino.

Como forma de reduzir esse hiato, Ribeiro e Cury voltam a questionar o processo formativo do professor. Eles sugerem mudanças no foco dos cursos no que diz respeito ao ensino de Álgebra, defendendo a tese de que a formação deve estar "mais ancorada nas práticas de sala de aula do que na apresentação formal de conteúdos matemáticos" (Ribeiro \& Cury, 2015, p. 101).

Os autores buscam ainda consolidar a ideia de que o conhecimento matemático, mesmo sendo fundamental para o professor, não é suficiente para o desenvolvimento de um trabalho de forma efetiva. Nessa direção, lembram que os conceitos de equação e função são fundamentais na formação do professor e que este profissional precisa também saber lidar com as dificuldades dos estudantes ou com respostas e perguntas inesperadas.

Portanto, é possível perceber que a obra se revela não somente uma significativa fonte de consulta para pesquisadores interessados no estudo do tema. De fato, os autores abordam importantes questões que devem se constituir em objeto de atenção por parte de profissionais envolvidos com a formação de professores.

Finalmente cumpre destacar ainda que a obra transcende o objetivo de oferecer uma visão geral dos conceitos de equação e função sob esta ótica de formação de professores. Este livro configura-se como material de indiscutível valor para educadores que atuam na Educação Básica. Com efeito, ao longo dos capítulos, Ribeiro e Cury trazem discussões que podem contribuir para que o profissional amplie os seus conhecimentos que são necessários para o desenvolvimento do trabalho em sala de aula. Além disso, considerações importantes são levantadas, colaborando para que se possa repensar a prática pedagógica, privilegiando a construção de significados por parte dos alunos e rompendo com uma prática de ensino tradicional de Álgebra que ainda é ancorada na repetição de técnicas.

Submetido em: 25/09/2015

Aceito em: 11/02/2016 